\title{
Dimensi Metrik Pada Graf Starbarbell dan Hasil Operasi Edge Corona Pada Graf Cycle dan Graf Path
}

\author{
Putri Dea Sari \\ Universitas Sebelas Maret \\ e-mail: pdeasari@gmail.com \\ Tri Atmojo Kusmayadi \\ Universitas Sebelas Maret \\ e-mail: tri.atmojo.kusmayadi@staff.uns.ac.id
}

\begin{abstract}
Let $G$ be a connected graph with vertex set $V(G)$ and edge set $E(G)$. Distance between vertex $u$ and $v$ is the shortest path from $u$ to $v$, denoted by $d(u, v)$. For an ordered set $W \subset V(G), W$ is resolving set of $G$ if every pair of vertices in $G$ are resolved by some vertex of $W$. Resolving set with minimum cardinality is called metric basis of $G$. The number of element from some basis in $G$ is called metric dimension, denoted by $\operatorname{dim}(G)$. In this research, we determine the metric dimension of starbarbell graph and edge corona graph $C_{m} \circ P_{n}$. The results show that the metric dimension of starbarbell graph is $\operatorname{dim}\left(S B_{m_{1}, m_{2 n} m_{n}}\right)=\sum_{i=1}^{n}\left(m_{i}-2\right) ; \operatorname{dim}\left(C_{m} \circ P_{n}\right)=2$ for $n=1, m=3$, or $m$ even $(m \geq 4) ; \operatorname{dim}\left(C_{m} \circ P_{n}\right)=3$ for $n=1$ and $m$ odd $(m \geq 5)$; $\operatorname{dim}\left(C_{m} \circ P_{n}\right)=2\left\lceil\frac{2 n}{5}\right\rceil+\left\lceil\frac{2 n-2}{5}\right\rceil$ for $m=3$ and $\geq 2 ;$ and also $\operatorname{dim}\left(C_{m} \circ P_{n}\right)=m\left\lceil\frac{2 n-2}{5}\right\rceil$ for $m>3$ and $n \geq 2$.
\end{abstract}

Keywords: metric dimension, resolving set, starbarbell graph, $C_{m} \circ P_{n}$ graph

Abstrak: Misal $G$ adalah graf terhubung dengan himpunan vertex $V(G)$ dan himpunan edge $E(G)$. Jarak di antara dua vertex $u$ dan $v$ adalah panjang path terpendek dari $u$ ke $v$, yang dinyatakan dengan $d(u, v)$. Untuk suatu himpunan terurut $W \subset V(G), W$ adalah himpunan pembeda dari $G$ jika setiap pasang vertex dalam $G$ dibedakan oleh suatu vertex dari W. Himpunan pembeda dengan kardinalitas minimum disebut basis metrik dari $G$. Banyaknya elemen dari suatu basis dalam $G$ disebut dimensi metrik, dinyatakan dengan dim (G). Dalam penelitian ini ditentukan dimensi metrik dari graf starbarbell dan graf edge corona $C_{m} \circ P_{n}$. Hasilnya menunjukkan bahwa dimensi metrik dari graf starbarbell adalah $\operatorname{dim}\left(S B_{m_{1}, m_{2}, m_{m} m_{n}}\right)=\sum_{i=1}^{n}\left(m_{i}-2\right) ; \operatorname{dim}\left(C_{m} \circ P_{n}\right)=2$ untuk $n=1$, $m=3$, atau $m$ genap $(m \geq 4) ; \operatorname{dim}\left(C_{m} \circ P_{n}\right)=3$ untuk $n=1$ dan $m$ ganjil $(m \geq 5)$; $\operatorname{dim}\left(C_{m} \circ P_{n}\right)=2\left\lceil\frac{2 n}{5}\right\rceil+\left\lceil\frac{2 n-2}{5}\right\rceil$ untuk $m=3$ dan $n \geq 2 ;$ dan juga $\operatorname{dim}\left(C_{m} \circ P_{n}\right)=m\left\lceil\frac{2 n-2}{5}\right\rceil$ untuk $m>3$ dan $n \geq 2$.

Kata kunci: dimensi metrik, himpunan pembeda, graf starbarbell, graf $C_{m} \circ P_{n}$ 


\section{Pendahuluan}

Tahun 1975, konsep dimensi metrik muncul dari himpunan pembeda yang diperkenalkan oleh Slater [9], yang mendefinisikan himpunan pembeda atau locating set $W$ sebagai himpunan dari vertex-vertex pada suatu graf $G$ sedemikian sehingga untuk setiap vertex di $G$ akan dihasilkan jarak yang berbeda terhadap setiap vertex di $W$. Dimensi metrik adalah kardinalitas minimum dari himpunan pembeda $W$. Kemudian Harary dan Melter [6] pada tahun 1976 menyebutkan himpunan pembeda sebagai resolving set. Hasil operasi edge corona dari graf cycle dan graf path dinotasikan dengan $C_{m} \diamond P_{n}$. Graf ini terbentuk dari salinan graf cycle $C_{m}$ dan $m$ salinan graf path $P_{n}$ kemudian menggabungkan dengan dua vertex ujung dari $e_{i} \in E\left(C_{\mathrm{m}}\right)$ ke setiap vertex $v_{j} \in V\left(P_{\mathrm{n}}\right)$ pada salinanke- $i$ dengan $i=1,2, \ldots, m_{1}$ dan $j=1,2, \ldots, n_{2}$.

Beberapa peneliti telah menemukan dimensi metrik pada beberapa kelas graf. Tahun 2000, Chartrand et al. [5] meneliti dimensi metrik graf path $P_{n}$, graf cycle $C_{n}$, dan graf lengkap $K_{n}$. Tahun 2005, Caceres et al. [3] meneliti dimensi metrik graf fan. Tahun 2009, Caceres et al. [4] meneliti dimensi metrik pada graf tak hingga. Tahun 2011, Bača et al. [1] meneliti dimensi metrik pada graf bipartit $k$-reguler. Tahun 2016, Kusmayadi et al. [8] meneliti dimensi metrik pada graf sunflower, graf $t$-fold wheel, dan graf $K_{1}+\left(P_{n} \odot P_{m}\right)$. Widodo [10] menentukan dimensi metrik dari helm graph dan double cones graph. Hasil penelitian tersebut membuat penulis tertarik untuk mencari dimensi metrik pada kelas graf lain yang belum pernah ditentukan, yaitu dimensi metrik pada graf starbarbell dan graf $C_{m} \diamond P_{n}$.

\section{Metode Penelitian}

Metode yang digunakan dalam penelitian ini adalah kajian pustaka yaitu dengan mengumpulkan referensi berupa buku-buku, jurnal maupun tulisan-tulisan yang dimuat di situs web. Dari metode ini, dapat ditentukan dimensi metrik pada graf starbarbell dan graf $C_{m} \diamond P_{n}$. Langkah-langkah yang dilakukan dalam penelitian ini diuraikan sebagai berikut.

1) Menentukan himpunan pembeda $W$ pada graf starbarbell dan graf $C_{m} \diamond P_{n}$.

2) Menghitung jarak setiap vertex dengan $W$ yang telah ditentukan, sedemikian sehingga setiap dua vertex berbeda pada graf starbarbell dan graf $C_{m} \diamond P_{n}$. mempunyai representasi yang berbeda terhadap $W$.

3) Menentukan dimensi metrik berdasarkan hasil yang diperoleh pada Langkah 2) pada graf starbarbell dan graf $C_{m} \diamond P_{n}$.

4) Membuat pembuktian dengan menyusun lema dan teorema berdasarkan hasil yang diperoleh.

5) Membuat kesimpulan 


\section{Hasil dan Pembahasan}

\subsection{Dimensi Metrik pada Graf Starbarbell}

Budianto dan Kusmayadi [2] mendefinisikan graf starbarbell $S B_{m_{1}, m_{2}, m, m_{n}}$ merupakan graf yang terbentuk dari sebuah graf $\operatorname{star} K_{1, n}$ dan ${ }^{n}$ graf lengkap $K_{m_{i}}$

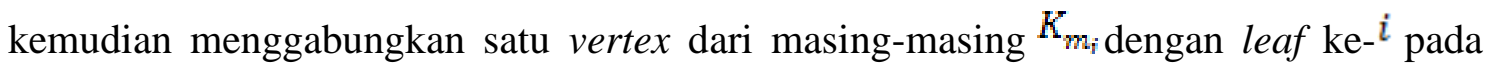
$K_{1, n}$ dengan $m_{i} \geq 3,1 \leq i \leq n$, dan $n \geq 2$. Ilustrasi dari graf starbarbell dapat dilihat pada Gambar 1.

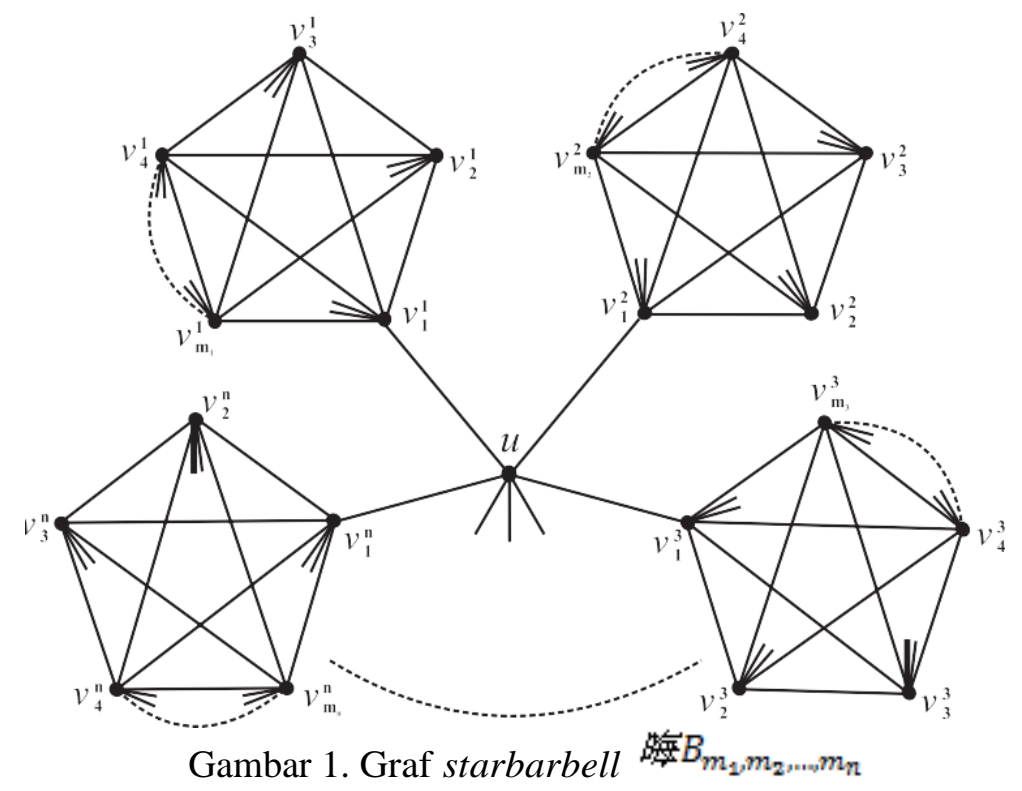

Lemma 3.1. Vertex pusat ${ }^{u}$ tidak termuat dalam basis manapun pada suatu graf starbarbell $S B_{m_{1}, m_{2}, \ldots, m} m_{n}$ :

BuKTI. Dibuktikan dengan kontradiksi. Andai ${ }^{P}$ adalah basis pada graf starbarbell $S B_{m_{1}, m_{2}, m_{2}, m_{n}}$ yang memuat vertex pusat ${ }^{u}$. Karena $P \backslash\{u\}$ bukan basis, terdapat vertex $v, v^{\prime} \in V\left(S B_{m_{1}, m_{\mathrm{n}}, m_{m} m_{n}}\right)$ sedemikian sehingga $d(v, x)=d\left(v^{\prime}, x\right)$ untuk setiap $x \in P \backslash\{u\}$. Jelas bahwa $P=\{u\}$ bukan basis, sehingga $P \backslash\{u\} \neq \emptyset$. Jika tidak 
berlaku $v=u$ dan $v^{\prime}=u$ maka $d(v, u)=d\left(v^{\prime}, u\right)$ dan ${ }^{P}$ bukan basis pada graf starbarbell $S B_{m_{1}, m_{2}, m_{2} m_{n}}$. Misal diasumsikan $v^{\prime}=u$ dan tanpa mengurangi keumuman, $v$ adalah vertex $v_{2}^{2}$. Pada kasus ini, diperoleh $d\left(v_{2}^{2}, x\right)=d(u, x)$ untuk setiap $\in P$. Artinya ${ }^{P}$ bukan basis. Sehingga terbukti bahwa vertex pusat $u$ tidak termuat dalam basis manapun.

Teorema 3.2. Untuk setiap graf starbarbell ${ }^{S B_{m_{1}, m_{2}, m_{2} m_{n}} \text { dengan }} m_{i} \geq 3$ untuk setiap $1 \leq i \leq n$ dan ${ }^{n \geq 2}$ berlaku $\operatorname{dim}\left(S B_{m_{1}, m_{2}, \ldots, m_{n}}\right)=\sum_{i=1}^{n}\left(m_{i}-2\right)$.

BUKTI. Diberikan graf starbarbell $S B_{m_{1}, m_{n^{\prime} m, m} m_{n} \text { dengan }} m_{i} \geq 3$ untuk setiap $1 \leq i \leq n$ dan $n \geq 2$.

i) Akan ditunjukkan bahwa $\operatorname{dim}\left(S B_{m_{1}, m_{n, m} m_{n}}\right) \leq \sum_{i=1}^{n}\left(m_{i}-2\right)$.

Dengan Lema 3.1, dipilih himpunan $W=\left\{v_{j}^{i}\right\}$ dengan $1 \leq i \leq n$ dan $2 \leq j \leq m_{i}-1$. Kardinalitas dari $W$ yaitu $\sum_{i=1}^{n}\left(m_{i}-2\right)$. Diperoleh representasi dari setiap vertex pada $S B_{m_{1}, m_{2}, m_{2} m_{n}}$ terhadap ${ }^{W}$ sebagai berikut

$$
\begin{aligned}
& r\left(v_{1}^{1} \mid W\right)=(1,1, \cdots, 1,3,3, \cdots, 3, \cdots, 3,3, \cdots, 3), \\
& r\left(v_{2}^{1} \mid W\right)=(0,1, \cdots, 1,4,4, \cdots, 4, \cdots, 4,4, \cdots, 4), \\
& \vdots \\
& r\left(v_{m_{1}}^{1} \mid W\right)=(1,1, \cdots, 1,4,4, \cdots, 4, \cdots, 4,4, \cdots, 4), \\
& \vdots \\
& r\left(v_{1}^{n} \mid W\right)=(3,3, \cdots, 3,3,3, \cdots, 3, \cdots, 1,1, \cdots, 1), \\
& r\left(v_{2}^{n} \mid W\right)=(4,4, \cdots, 4,4,4, \cdots, 4, \cdots, 0,1, \cdots, 1), \\
& \vdots \\
& r\left(v_{m_{n}}^{n} \mid W\right)=(4,4, \cdots, 4,4,4, \cdots, 4, \cdots, 1,1, \cdots, 1), \\
& r(u \mid W)=(2,2, \cdots, 2,2,2, \cdots, 2, \cdots, 2,2, \cdots, 2) .
\end{aligned}
$$

Karena setiap vertex mempunyai representasi yang berbeda terhadap $W$, sehingga $W$ merupakan himpunan pembeda. 
ii) Akan ditunjukkan bahwa $\operatorname{dim}\left(S B_{m_{1}, m_{n, m} m_{n}}\right) \geq \sum_{i=1}^{n}\left(m_{i}-2\right)$. Ditunjukkan dengan kontradiksi, andaikan $W$ adalah himpunan pembeda dari graf starbarbell $S B_{m_{1}, m_{2}, m_{2} m_{n}}$ dengan $|W|<\sum_{i=1}^{n}\left(m_{i}-2\right)$. Jika dipilih himpunan $W=\left\{v_{x}^{1}, v_{x}^{y}\right\}$ dengan $2 \leq x \leq m_{i}-2$, $2 \leq y \leq n$, dan $2 \leq z \leq m y-1$, maka terdapat vertex $v_{m 1-1}^{1}, v_{m 1}^{1} \in V\left(S B_{m_{1}, m_{n, \ldots} m_{n}}\right)$ sedemikian sehingga terdapat representasi yang sama yaitu $r\left(v_{m_{1}-1}^{1} \mid W\right)=r\left(v_{m_{1}}^{1} \mid W\right)=(1,1, \cdots, 1,4,4, \cdots, 4, \cdots, 4,4, \cdots, 4)$. Hal ini kontradiksi dengan pengandaian, sehingga $\operatorname{dim}\left(S B_{m_{1}, m_{n, m}, m_{n}}\right) \geq \sum_{i=1}^{n}\left(m_{i}-2\right)$.

Dari i) dan ii), terbukti bahwa $\operatorname{dim}\left(S B_{m_{1}, m_{n,}, m_{n}, m_{n}}\right)=\sum_{i=1}^{n}\left(m_{i}-2\right)_{\square}$

\subsection{Dimensi Metrik pada Graf ${ }^{\circ}{ }_{m}{ }^{\circ} P_{n}$}

Definisi dari edge corona dua buah graf diambil dari Hou and Shiu [7]. Graf $C_{m} \circ P_{n}$ adalah suatu graf yang diperoleh dari hasil operasi edge corona graf cycle $C_{m}$ dengan graf path $P_{n \text { dengan }} m \geq 3$ dan $n \geq 1$. Ilustrasi graf $C_{m} \circ P_{n \text { dapat dilihat pada }}$ Gambar 2.

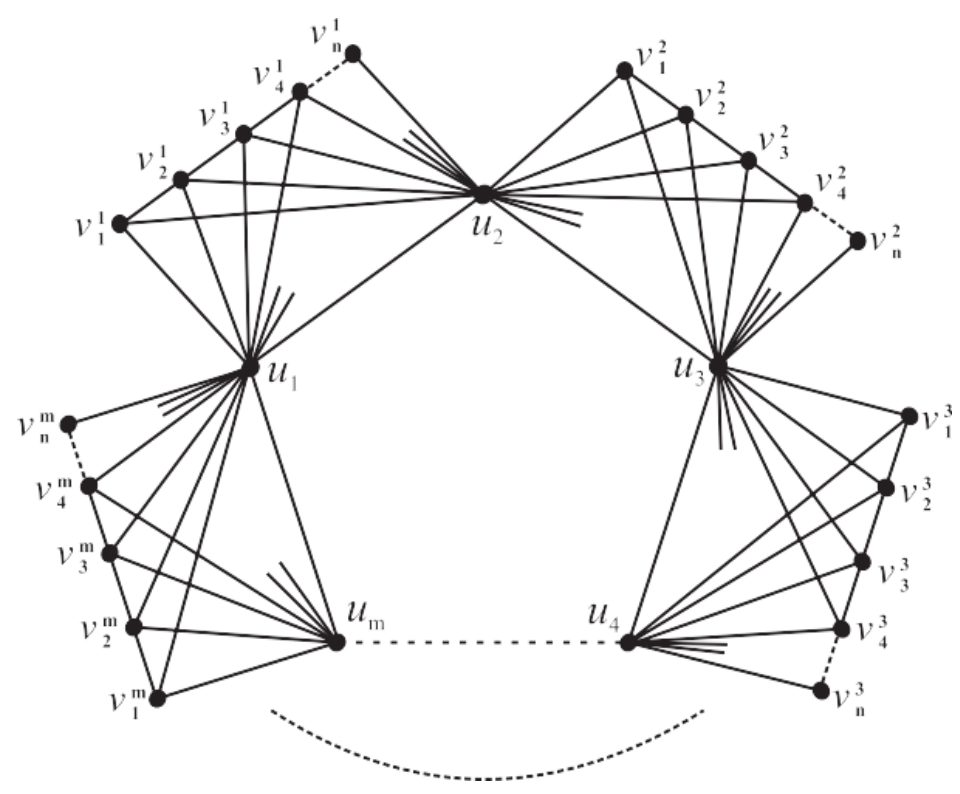

Gambar 2. Graf $C_{m} \circ P_{n}$ 
Berikut ini diberikan hasil dimensi metrik pada graf $C_{m} \bullet P_{n}$.

Lema 3.3. Vertex $u_{i} \in V\left(C_{m}\right)$ dengan $1 \leq i \leq m$ dan $m \geq 3$ tidak termuat dalam basis manapun pada graf $C_{m} \circ P_{n}$.

BUKTI. Dibuktikan dengan kontradiksi. Andai $P$ adalah basis pada graf $C_{m}{ }^{\circ} P_{n}$ yang memuat $u_{i}$. Karena $P \backslash\left\{u_{i}\right\}$ bukan basis, terdapat vertex $v, v^{\prime} \in V\left(C_{m}{ }^{\circ} P_{n}\right)$ sedemikian sehingga $d(v, x)=d\left(v^{\prime}, x\right)$ untuk setiap $x \in P \backslash\left\{u_{i}\right\}$. Jelas bahwa $P=\left\{u_{i}\right\}$ bukan basis, sehingga $P \backslash\left\{u_{i}\right\} \neq \emptyset$. Jika tidak berlaku $v=u_{i}$ dan $v^{\prime}=u_{i}$ maka $d\left(v, u_{i}\right)=d\left(v^{\prime}, u_{i}\right)$ dan $P^{P}$ bukan basis pada graf $C_{m}{ }^{\circ} P_{n}$. Misal diasumsikan $v^{\prime}=u_{i}$ dan tanpa mengurangi keumuman, ${ }^{v}$ adalah vertex $v_{2}^{\frac{\pi}{i}}$. Pada kasus ini, diperoleh $d\left(v_{2}^{i}, x\right)=d\left(u_{i}^{i}, x\right)$ untuk setiap $x \in P$. Artinya $P$ bukan basis. Sehingga terbukti bahwa vertex $u_{i}$ dengan $1 \leq i \leq m$ tidak termuat dalam basis manapun.

Teorema 3.4. Untuk setiap graf $C_{m}{ }^{\circ} P_{n}$ dengan $m \geq 3$ dan $n \geq 1$ berlaku

$$
\operatorname{dim}\left(C_{m} \circ P_{n}\right)=\left\{\begin{aligned}
2, & m=3 \text { v genap }(m \geq 4), n=1 ; \\
3, & m \text { ganjil }(m \geq 5), n=1 ; \\
2\left\lceil\frac{2 n}{5}\right\rceil+\left\lceil\frac{2 n-2}{5}\right\rceil, & m=3, n \geq 2 ; \\
m\left\lceil\frac{2 n-2}{5}\right\rceil, & m>3, n \geq 2 .
\end{aligned}\right.
$$

BUKTI Pembuktian rumus umum dimensi metrik pada graf $C_{m} \circ P_{n}$ terbagi menjadi empat kasus sebagai berikut.

Kasus 1. $m=3$ atau $m$ genap $(m \geq 4), n=1$.

1. Misalkan ${ }^{m}$ bilangan bulat, $m=3$. Pilih $W=\left\{v_{1}^{1}, v_{1}^{2}\right\} \subset V\left(P_{1}\right)$, diperoleh representasi semua vertex $V\left(C_{3} \circ P_{1}\right)$ terhadap $W_{\text {sebagai berikut }}$

$$
\begin{array}{lll}
r\left(u_{1} \mid W\right)=(1,2), & r\left(u_{3} \mid W\right)=(2,1), & r\left(v_{1}^{2} \mid W\right)=(2,0), \\
r\left(u_{2} \mid W\right)=(1,1), & r\left(v_{1}^{1} \mid W\right)=(0,2), & r\left(v_{1}^{3} \mid W\right)=(2,2) .
\end{array}
$$

2. Untuk $m$ genap $(m \geq 4)$ dan $n=1$.

Misalkan ${ }^{m}$ bilangan bulat genap $m \geq 4$. Pilih $W=\left\{v_{1}^{1}, v_{1}^{\frac{m}{2}}\right\} \subset V\left(P_{1}\right)$, diperoleh representasi semua vertex $V\left(C_{m}{ }^{\circ} P_{1}\right)$ terhadap $W_{\text {sebagai berikut }}$ 


$$
\begin{aligned}
& r\left(u_{i} \mid W\right)=\left\{\begin{aligned}
\left(1, \frac{m}{2}\right), & i=1 ; \\
\left(\frac{m}{2}, 1\right), & i=\frac{m+2}{2} \\
\left(i-1, \frac{m}{2}+1-i\right), & 2 \leq i \leq \frac{m}{2} \\
\left(m+2-i, i-\frac{m}{2}\right), & \frac{m+4}{2} \leq i \leq m
\end{aligned}\right. \\
& r\left(v_{1}^{i} \mid W\right)=\left\{\begin{aligned}
\left(0, \frac{m}{2}\right), & i=1 ; \\
\left(i, \frac{m}{2}+1\right), & 2 \leq i \leq \frac{m-2}{2} ; \\
\left(i-1, \frac{m}{2}+1-i\right), & i=\frac{m}{2} ; \\
\left(2-i+m, 1+i-\frac{m}{2}\right), & \frac{m+2}{2} \leq i \leq m .
\end{aligned}\right.
\end{aligned}
$$

Dari 1 dan 2 , setiap vertex $V\left(C_{3} \circ P_{1}\right)$ dan $V\left(C_{m} \circ P_{n}\right)$ dengan $m$ genap $(m \geq$ 4) dan $n=1$ memiliki representasi yang berbeda terhadap $W$ maka $W$ adalah himpunan pembeda dengan 2 elemen. Berdasarkan karakterisasi dari Chartrand et al. [5] yang menyatakan $\operatorname{dim}(G)=1$ jika dan hanya jika $G=P_{n}(n \geq 2)$, karena $C_{3} \circ P_{1} \neq P_{n}(n \geq 2)$ maka diperoleh $\operatorname{dim}\left(C_{3} \circ P_{1}\right)=2$. Hal ini berlaku pula untuk $C_{m} \circ P_{n}$ dengan $m$ genap $(m \geq 4)$ dan $n=1$.

Kasus 2. $m_{\text {ganjil }}(m \geq 5), n=1$.

Misalkan $m$ bilangan bulat, $m \geq 5$. Pilih $W=\left\{v_{1}^{m}, v_{1}^{1}, v_{1}^{\frac{m-2}{2}}\right\} \subset V\left(P_{n}\right)$, diperoleh representasi semua vertex $V\left(C_{m}{ }^{\circ} P_{n}\right)$ terhadap $W$ sebagai berikut $r\left(u_{i} \mid W\right)=\left\{\begin{aligned}\left(1,1, \frac{m-1}{2}\right), & i=1 ; \\ \left(i, i-1, \frac{m+1}{2}-i\right), & 2 \leq i \leq \frac{m-1}{2} \\ (i, i-1,1), & i=\frac{m+1}{2} \\ \left(m+1-i, m+2-i, i-\frac{m-1}{2}\right), & \frac{m+3}{2} \leq i \leq m ;\end{aligned}\right.$

1. Untuk $m=5$. 


$$
r\left(v_{1}^{i} \mid W\right)=\left\{\begin{aligned}
(2,0,2), & i=1 \\
(3,2,0), & i=2 ; \\
\left(m-i+1, m-\left\lfloor\frac{m}{2}\right\rfloor, i-1\right), & i=3,4 \\
(0,2,3), & i=5 .
\end{aligned}\right.
$$

2. Untuk $m>5$.

$$
r\left(v_{1}^{i} \mid W\right)=\left\{\begin{aligned}
(2,0,2), & i=1 ; \\
(3,2,0), & i=2 \\
(i+1, i, i-1), & 3 \leq i \leq \frac{m-1}{2} \\
\left(m-i+1, m-\left[\frac{m}{2}\right], i-1\right), & \frac{m+1}{2} \leq i \leq \frac{m+3}{2} \\
(m-i+1, m-i+2, m-i+3), & \frac{m+5}{2} \leq i \leq m-1 ; \\
(0,2,3), & i=m .
\end{aligned}\right.
$$

Setiap vertex $V\left(C_{m} \circ P_{n}\right)$ memiliki representasi yang berbeda terhadap ${ }^{W}$ maka $W$ adalah himpunan pembeda dengan ${ }^{3}$ elemen. Selanjutnya ditunjukkan $C_{m} \circ P_{n}$ tidak memiliki himpunan pembeda dengan ${ }^{2}$ elemen. Andaikan $C_{m}{ }^{\circ} P_{n \text { memiliki himpunan }}$ pembeda ${ }^{W}$ dengan ${ }^{2}$ elemen, terdapat ${ }^{3}$ kemungkinan pemilihan vertex dari $W$. Akan tetapi, berdasarkan Lema 3.3 vertex $u_{i} \in V\left(C_{m}\right)$ dengan $1 \leq i \leq m$ dan $m \geq 3$ tidak termuat dalam basis manapun sehingga $W \subset V\left(P_{n}\right)$. Sehingga hanya ada 1 kemungkinan pemilihan vertex dari $W$ yaitu kedua vertex dari $W$ termasuk dalam $\left\{v_{1}^{m}: 1 \leq m \leq n\right\} \subset V\left(P_{1}\right)$

Misalkan salah satu vertex dalam $W$ adalah $v_{1}^{1}$ dan vertex lainnya adalah $v_{1}^{s}$, dengan $(2 \leq s \leq m)$. Diperoleh representasi yang sama yaitu

$$
\begin{aligned}
& r\left(u_{m} \mid W\right)=r\left(v_{1}^{m} \mid W\right)=(2, s+1), 2 \leq s \leq \frac{m-1}{2} ; \\
& r\left(u_{m-1} \mid W\right)=r\left(v_{1}^{3} \mid W\right)=(3, s-2), s=\frac{m+1}{2} ; \\
& r\left(u_{m-1} \mid W\right)=r\left(v_{1}^{4} \mid W\right)=(3, s-2), s=\frac{m+3}{2} ; \text { dan } \\
& r\left(u_{3} \mid W\right)=r\left(v_{1}^{2} \mid W\right)=(2, m-s+2), \frac{m-5}{2} \leq s \leq m .
\end{aligned}
$$

Untuk $W=\left\{v_{1}^{t}, v_{1}^{s}\right\}$, dengan $2 \leq t<s \leq m$, selalu diperoleh dua vertex $V\left(C_{m}{ }^{\circ} P_{n}\right)$ yang memiliki representasi sama terhadap $W$. Hal ini kontradiksi 
dengan pengandaian. Diperoleh representasi yang sama terhadap ${ }^{W}$. Oleh karena itu, $V\left(C_{m} \circ P_{n}\right)$ tidak memiliki himpunan pembeda dengan ${ }^{2}$ elemen. Himpunan pembeda dengan kardinalitas minimum dari $V\left(C_{m} \circ P_{n}\right)$ adalah ${ }^{3}$ elemen, sehingga terbukti $\operatorname{dim}\left(C_{m} \circ P_{n}\right)=3$, untuk ${ }^{m}$ ganjil $(m \geq 5)$ dan $n=1$.

Kasus 3. $m=3$ dan $n \geq 2$.

Graf $C_{m} \circ P_{n}$ dengan $m=3$ dan $n \geq 2$ mempunyai himpunan vertex $V\left(C_{m} \circ P_{n}\right)=\left\{u_{1}, u_{2}, u_{3}, v_{1}^{1}, v_{2}^{1}, \ldots, v_{n}^{1}, v_{1}^{2}, v_{2}^{2}, \ldots, v_{n}^{2}, v_{1}^{3}, v_{2}^{3}, \ldots, v_{n}^{3}\right\}$. Berdasarkan Lema $^{3.2}$, vertex $u_{i} \in V\left(C_{m}\right)$ dengan $1 \leq i \leq n$ dan $m \geq 3$ tidak termuat dalam basis manapun sehingga $W \subset V\left(P_{n}\right)$. Pembuktian dibagi menjadi ${ }^{2}$ bagian yaitu untuk path $P_{s \text { dengan }} s=1,2$ dan path $P_{i \text { dengan }} i=3$

1. $\quad$ Path $P_{s}$ dengan $s=1,2$.

(a) Satu dari dua vertex $v_{1}^{s}, v_{2}^{s}$ dengan $s=1,2$ merupakan elemen $W$. Jika $v_{1}^{s}, v_{2}^{s} \notin W$ maka $d\left(v_{1}^{s}, u_{p}\right)=d\left(v_{2}^{s}, u_{p}\right)=1$ dan $d\left(v_{1}^{s}, v_{q}^{p}\right)=d\left(v_{2}^{s}, v_{q}^{p}\right)=2$ dengan $p=2,3$ dan $q=1,2$ sehingga $r\left(v_{1}^{s} \mid W\right)=r\left(v_{2}^{s} \mid W\right)$. Dipilih vertex $v_{2}^{s}$.

(b) Jika setiap vertex $v_{3}^{s}, v_{4}^{s}, v_{5}^{s} \notin W$ maka $r\left(v_{1}^{s} \mid W\right)=r\left(v_{3}^{s} \mid W\right)$ dan $r\left(v_{4}^{s} \mid W\right)=r\left(r_{5}^{s} \mid W\right)$. Sehingga salah satu dari ketiga vertex tersebut merupakan elemen $W$. Misal dipilih $v_{3}^{s} \in W$, terdapat dua vertex dengan representasi sama yaitu $r\left(v_{5}^{s} \mid W\right)=r\left(v_{1}^{s} \mid W\right)$. Jika dipilih $v_{5}^{s} \in W$ maka $r\left(v_{1}^{s} \mid W\right)=r\left(v_{3}^{s} \mid W\right)$. Sehingga $v_{3}^{s}, v_{5}^{s} \notin W$, dipilih $v_{4}^{s} \in W$.

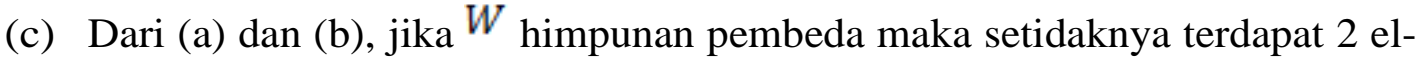
emen dari setiap 5 vertex. Tanpa mengurangi keumuman misal dipilih $n=9$, terdapat 4 elemen $W$. Jika dipilih $v_{2}^{s}, \sim_{4}^{s}, v_{7}^{s}, v_{9}^{s} \in W$ maka diperoleh 2 pasang vertex dengan representasi berbeda terhadap $W$ sehingga vertex tesebut merupakan elemen $W$. Pada path $P_{s}$, vertex $v_{n}^{s}$ dengan $n \equiv 1,3(\bmod 5)$ harus menambahkan vertex $v_{n_{\max }}^{s}$ ke dalam elemen $W$. Jika $v_{n_{\max }} \notin W$ maka

(d) $r\left(v_{n_{\max }}^{1} \mid W\right)=r\left(v_{n_{\max }}^{2} \mid W\right)$

Dari (a), (b), dan (c) diperoleh pengambilan $W=\left\{v_{2+5 p}^{s}, v_{4+5 r}^{s}\right\}$ dengan $p=0,1, \cdots,\left\lceil\frac{n-5}{5}\right\rceil$ dan $r=0,1, \cdots,\left\lceil\frac{n-7}{5}\right\rceil$. Jika terdapat $v_{2+5\left\lceil\frac{n-5}{5}\right\rceil}^{s}=v_{n+1}^{s}$ atau 


$$
\begin{aligned}
& v_{4+5\left\lceil\frac{n-7}{5}\right\rceil}^{s}=v_{n+1}^{s} \text { maka } v_{n_{\max }}^{s} \text { elemen } W \text {. Akibatnya kardinalitas pada path } \\
& P_{s \text { adalah }} 2\left(\left\lceil\frac{n}{5}\right\rceil+\left\lceil\frac{2 n-2}{5}\right\rceil\right)=2\left\lceil\frac{2 n}{5}\right\rceil .
\end{aligned}
$$

2. $\quad$ Path $^{P_{i} \text { dengan }} i=3$.

(a) Jika setiap vertex $v_{1}^{\frac{i}{i}}, v_{2}^{\frac{i}{t}}, v_{3}^{\frac{x}{i}} \notin W$ maka $r\left(v_{1}^{i} \mid W\right)=r\left(v_{2}^{i} \mid W\right)=r\left(v_{3}^{\frac{i}{i}} \mid W\right)$. Sehingga salah satu dari ketiga vertex tersebut adalah elemen $W$. Misal dipilih $v_{1}^{i} \in W$, terdapat dua vertex dengan representasi sama yaitu $r\left(v_{2}^{i} \mid W\right)=r\left(v_{3}^{i} \mid W\right)$. Sama halnya jika dipilih $v_{2}^{\frac{i}{i}} \in W$ maka $r\left(v_{1}^{t} \mid W\right)=r\left(v_{3}^{t} \mid W\right)$. Sehingga $v_{1}^{\frac{i}{i}}, v_{2}^{i} \notin W$, dipilih $v_{3}^{i} \in W$.

(b) Jika setiap vertex $v_{4}^{\frac{x}{t}}, v_{5}^{\frac{x}{t}} \notin W$ maka $r\left(v_{4}^{\frac{t}{t}} \mid W\right)=r\left(v_{5}^{\frac{i}{t}} \mid W\right)$. Sehingga salah satu dari kedua vertex tersebut adalah elemen $W$. Dipilih $v_{4}^{i} \in W$, terdapat dua vertex dengan representasi sama yaitu $r\left(v_{1}^{i} \mid W\right)=r\left(v_{6}^{i} \mid W\right)$. Berarti $v_{4}^{i} \notin W$, sehingga dipilih $v_{5}^{i} \in W$.

(c) Dari (a) dan (b), terdapat setidaknya 2 elemen himpunan pembeda $W$ dari setiap 5 vertex. Tanpa mengurangi keumuman misal dipilih $n=10$, terdapat 4 elemen $W$. Jika dipilih $v_{3}^{i}, v_{5}^{i}, v_{8}^{t}, v_{10}^{i} \in W$. Diperoleh 2 pasang vertex dengan representasi berbeda terhadap $W$ sehingga vertex tesebut merupakan elemen $W$. Pada path ${ }^{P_{i}}$, vertex $v_{n}^{\frac{\pi}{i}}$ dengan $n \equiv 2,4(\bmod 5)$ harus menambahkan vertex $v_{n_{\max }^{i}}^{\frac{\pi}{2}}$ ke dalam elemen $W$. Jika $v_{n_{\max }}^{\frac{\pi}{i}} \notin W$ maka $r\left(v_{n_{m n}}^{\frac{i}{i}} \mid W\right)=r\left(v_{n_{m n}-2}^{\frac{i}{i}} \mid W\right)$.

Dari (a), (b), dan (c) diperoleh pengambilan $W=\left\{v_{3+5 p}^{i}, v_{5 r}^{i}\right\}$ dengan $p=0,1, \cdots,\left\lceil\frac{n-6}{5}\right\rceil$ dan $r=1,2, \cdots,\left\lceil\frac{n-3}{5}\right\rceil$. Jika terdapat $v_{3+5\left\lceil\frac{n-6}{5}\right\rceil}^{\frac{n}{i}}=v_{n+1}^{\frac{i}{i}}$ atau $v_{\left.5 \Gamma \frac{i}{5}\right]}^{\frac{n}{n-3}}=v_{n+1}^{\frac{i}{i}}$ maka $v_{n_{\max }}^{\frac{i}{i}}$ elemen $W$. Akibatnya kardinalitas pada path ${ }^{P_{i}}$ adalah $\left\lceil\frac{n-1}{5}\right\rceil+\left\lceil\frac{n-3}{5}\right\rceil=\left\lceil\frac{2 n-2}{5}\right\rceil$.

Dari 1 dan 2 berakibat kardinalitas dari $W$ adalah jumlahan dari kardinalitas $W$ pada kedua path yaitu $P_{s}$ dan $P_{i}$. Diperoleh kardinalitas dari $W$ adalah $2\left\lceil\frac{2 n}{5}\right\rceil+\left\lceil\frac{2 n-2}{5}\right\rceil$. Sehingga $\operatorname{dim}\left(C_{3} \circ P_{\text {ळ }}\right)=2\left\lceil\frac{2 n}{5}\right\rceil+\left\lceil\frac{2 n-2}{5}\right\rceil$ untuk $n \geq 2$. 
Kasus 4. $m>3$ dan $n \geq 2$.

Graf $C_{m} \circ P_{n}$ dengan $m>3$ dan $n \geq 2$ mempunyai himpunan vertex $V\left(C_{m} \circ P_{n}\right)=\left\{u_{1}, u_{2}, \ldots, u_{m}, v_{1}^{1}, v_{2}^{1}, \ldots, v_{n}^{1}, v_{1}^{2}, v_{2}^{2}, \ldots, C_{n}^{2}, v_{1}^{3}, v_{2}^{3}, \ldots, v_{n}^{m}\right\}$. Misal dipilih suatu himpunan tak kosong $W \subset V\left(P_{n}\right)$. Analog dengan Kasus 3 poin 2, untuk path $P_{\bar{i}}$ dengan $1 \leq i \leq m$, diperoleh pula pengambilan $W=\left\{v_{3+5 p}^{i}, v_{5 r}^{i}\right\}$ dengan $p=0,1, \cdots,\left\lceil\frac{n-6}{5}\right\rceil$ dan $r=1,2, \cdots,\left\lceil\frac{n-3}{5}\right\rceil$. Jika terdapat $v_{3+5\left\lceil\frac{n-6}{5}\right\rceil}^{i}=v_{n+1}^{i}$ atau $v_{\left.5 \Gamma \frac{n-3}{5}\right]}^{i}=v_{n+1}^{i}$ maka $v_{n_{\max }^{i}}^{i}$ elemen $W$. Terdapat $m$ copy graf $P_{n}$ pada $C_{m} \circ P_{n}$. Sebanyak $\left[\frac{2 n-2}{5}\right\rceil_{\text {vertex pada setiap copy dari graf }} P_{n}$ merupakan elemen $W$. Akibatnya kardinalitas $W_{\text {adalah }}\left[\frac{2 n-2}{5}\right\rceil$. Sehingga terbukti bahwa $\operatorname{dim}\left(C_{m}{ }^{\circ} P_{n}\right)=m\left\lceil\frac{2 n-2}{5}\right\rceil$ untuk $^{m>3}$ dan $n \geq 2$.

\section{Kesimpulan dan Saran}

Berdasarkan hasil dan pembahasan di atas dapat disimpulkan bahwa dimensi metrik pada graf starbarbell $S B_{m_{1}, m_{2}, m_{2} m_{n}}$ adalah

$$
\operatorname{dim}\left(S B_{m_{1}, m_{2}, m m_{n}}\right)=\sum_{i=1}^{n}\left(m_{i}-2\right) .
$$

Dimensi metrik pada graf $C_{m}{ }^{\circ} P_{n}$ adalah

$$
\operatorname{dim}\left(C_{m} \circ P_{n}\right)=\left\{\begin{aligned}
2, & m=3 \vee \text { genap }(m \geq 4), n=1 ; \\
3, & m \text { ganjil }(m \geq 5), n=1 ; \\
2\left\lceil\frac{2 n}{5}\right\rceil+\left\lceil\frac{2 n-2}{5}\right\rceil, & m=3, n \geq 2 ; \\
m\left\lceil\frac{2 n-2}{5}\right\rceil, & m>3, n \geq 2 .
\end{aligned}\right.
$$

Saran yang diberikan adalah untuk menentukan dimensi metrik pada kelas graf yang belum pernah diteliti, misalnya graf king dan hasil operasi edge corona pada graf path dan graf lengkap. 


\section{Ucapan Terima Kasih}

Penulis mengucapkan terima kasih atas dukungan dana penelitian anggaran tahun 2019 dari Program Studi Matematika, Fakultas Matematika dan Ilmu Pengetahuan Alam, Universitas Sebelas Maret Surakarta, Indonesia.

\section{Daftar Pustaka}

[1] Bača M, Baskoro E T, Salman A N M, Saputro S W and Suprijanti D, The metric dimension of regular bipartite graphs, Bull. Math. Soc. Sci. Math. Roumanie Tome 54, 15-28, 2011.

[2] Budianto W T and Kusmayadi T A, The local metric dimension of starbarbell graph, $K_{m} \odot P_{n}$ graph, and Möbius ladder graph, J. Phys.: Conf. Ser. 1008, 012050, 2018.

[3] Caceres J, Hernando C, Mora M, Pelayo I M, Puertas M L and Seara C, On the metric dimension of some families of graphs, Electronic Notes in Discrete Math. 22, 129-133, 2005.

[4] Caceres J, Hernando C, Mora M, Pelayo I M and Puertas M L, On the metric dimension of infinite graphs, Electronic Notes in Discrete Math. 35, 1-17, 2009.

[5] Chartrand G, Eroh L, Johnson M and Oellermann O, Resolvability in graphs and the metric dimension of graph, Discrete Appl. Math 105, 98-113, 2000.

[6] Harary F and Melter R A, On the metric dimension of a graph, Ars Combinatoria 2, 191-195, 1976.

[7] Hou Y and Shiu W, The spectrum of the edge corona of two graphs, Electronic Journal of Linear Algebra 20, 586-594, 2010.

[8] Kusmayadi T A, Kuntari S, Fikri A F, Rahmadi D and Pradana H C, The metric dimension of sunflower, $t$-fold wheel, and $K_{1}+\left(P_{n} \odot P_{m}\right)$, Far East Journal of Mathematical Sciences (FJMS) 99, 687-698, 2016.

[9] Slater P J, Dominating and reference sets in a graph, J. Math. Phys. Sci. 22, 445-455, 1988.

[10] Widodo B J, Kusmayadi T A and Kuntari S, Metric dimension of helm graph and double cones graph, AIP Conference Proceedings 1746, 020049, 2016. 